\title{
TEKS KHUTBAH JUMAAT NEGERI JOHOR 2017-2018: Analisis Tajuk Dan Status Hadith Dalam Teks
}

\author{
Munirah binti Zakaria \\ Akademi Pengajian Islam Kontemporari (ACIS) \\ Universiti Teknologi MARA (UiTM) Cawangan Melaka \\ Email:munirah188@uitm.edu.my \\ Nazrudin bin Hashim \\ Akademi Pengajian Islam Kontemporari (ACIS) \\ Universiti Teknologi MARA (UiTM) Cawangan Melaka \\ Email:nazrudin@uitm.edu.my \\ Mohd Zainodin bin Mustaffa \\ Akademi Pengajian Islam Kontemporari (ACIS) \\ Universiti Teknologi MARA (UiTM) Cawangan Melaka \\ Email:mohdz334@uitm.edu.my \\ Kamarulzaman bin Sulaiman \\ Akademi Pengajian Islam Kontemporari (ACIS) \\ Universiti Teknologi MARA (UiTM) Cawangan Melaka \\ Email: kamar149@uitm.edu.my \\ Syaimak binti Ismail \\ Akademi Pengajian Islam Kontemporari (ACIS) \\ Universiti Teknologi MARA (UiTM) Cawangan Melaka \\ Email:syaimak@uitm.edu.my \\ Farah Hamizah binti Samsuddin \\ Akademi Pengajian Islam Kontemporari (ACIS) \\ Universiti Teknologi MARA (UiTM) Cawangan Melaka \\ Email: farah848@uitm.edu.my
}

\begin{abstract}
Abstrak
Teks khutbah negeri Johor merupakan satu platform penting dalam memberi peringatan serta nasihat kepada masyarakat Islam yang berada di Johor. Ia merupakan medium terbaik bagi menyampaikan pesanan kepada umat Islam berkenaan isu akidah, Syariah dan akblak serta isu-isu semasa yang berlaku di negeri Johor. Kajian ini memfokuskan kepada dua aspek, iaitu; bentuk pemiliban tajuk khutbah dan status hadith yang digunakan untuk. menyokong tajuk k.hutbah. Kedua-dua kaedah kualitatif dan kuantitatif diimplementasikan bagi menjawab objektif serta persoalan berkaitan penyelidikan. Selain kaedah analisis kandungan, kaedah takhrij hadith juga digunakan dalam kajian ini bagi menentukan status hadith, manakala analisis deskriptif diperoleh menggunakan perisian Statistical Packages for Social Sciences [SPSS 26.0]. Hasil kajian mendapati tajuk-tajuk teks khutbah sepanjang tahun 2017-2018 bersifat mendidik selain memberikan input-input penting berkaitan isu-isu agama dan membahaskan topik semasa yang berlaku di negeri Johor dengan sokongan dalil ayat al-quran dan hadith yang betepatan dengan tajuk. Namun begitu, penggunaan hadith dhaif di dalam teks khutbah perlu diberi perhatian oleh penulis supaya maklumat yang disampaikan tidak mengelirukan masyarakat.
\end{abstract}

Kata Kunci: Teks Khutbah, JAINJ, 2017-2018, Analisis, Tajuk, Status Hadith

\section{Abstract}

The Johor public sermon text is an important platform in providing warnings and advice to the Muslim community residing in Johor. He is the best medium for conveying orders to Muslims regarding issues of faith, Sharia and morals as well as issues during the prevailing country of Johor. This study focuses on two aspects, namely; the form of khutbah editorial selection and the status of hadiths used to support the khutbah editorial. Both qualitative and quantitative methods are implemented to answer objectives and problems related to investigation. Apart from the content analysis method, the hadith takhrij method is also used in this study to determine the status of the hadiths, when the descriptive analysis is obtained using Statistical Packages for Social Sciences [SPSS 26.0]. The results of the study found that the text of the sermon throughout 2017-2018 was educational in addition to providing important input related to religious issues and discussing topics during the period prevailing in Johor country with the support of the arguments of the al-

NUSANTARA; Journal for Southeast Asian Islamic Studies

Vol. 15, No. 2, Desember 2019 
Munirah binti Zakaria, dkk: Teks Khuthbah Jumaat Negerei Johor...

Quran and hadith verses that coincide with the editorial. However, the use of the badith dhaif in the sermon text needs to be given attention by the author so that the information conveyed does not confuse the public.

Keywords: Sermon Text, JAINJ, 2017-2018, Analysis, Headings, Hadith Status

\section{PENDAHULUAN}

Solat Jumaat merupakan satu kewajipan yang harus ditunaikan oleh setiap umat Islam tidak kira walau di mana jua mereka berada. Khutbah Jumaat pula merupakan syarat wajib yang telah disyariatkan sewaktu zaman Rasullulah lagi selain memperlihatkan fungsi khutbah yang merangkumi pelbagai bidang sebagai medium komunikasi secara verbal. (Zulkiple Abd Ghani, 2003 h. 84). Khutbah Jumaat adalah asas kepada kekuatan umat Islam dalam usaha, memahami dan menghayati al-quran. Isi kandungan khutbah mampu menyerap dengan baik ke dalam fikiran dan jiwa pendengar disaat mereka sedang memberi tumpuan dalam soal ibadah. Setiap perkara yang keluar daripada hati akan meninggalkan kesan yang menadalam ke dalam hati manusia. Khutbah Jumaat sangat berpengaruh dalam menyampaikan mesej pembangunan insaniah, pembangunan ukhrawi dan duniawi, persaudaraan, adab, akhlak, politik, ekonomi, kepimpinan dan menyebarkan pengaruh Islam kepada masyarakat. (Mohd Faizal bin Mat Nasan, 2002, h.3) Khutbah terutamanya khutbah Jumaat mempunyai potensi besar bagi membentuk agenda tertentu untuk meningkatkan taraf kehidupan umat Islam ke arah kecemerlangan dalam merangsang dan memupuk pembangunan sahsiah dan pemikiran kritis dan positif. Impak peranan yang dimainkan bergantung kepada keberkesanan penyampaian dan penerimaan jemaah. Ini kerana, khutbah Jumaat merupakan asas tindakan mingguan bagi setiap individu muslim dalam masyarakat umpamanya bermula dengan menanam minat untuk memahami isu berfikir, berbahas, membuat keputusan dan seterusnya melakukan perubahan sikap sama ada kepada diri atau keluarga selari dengan kehendak isi khutbah. (Hj Abdullah bin Mat, 2003, h. 2) Walaupun sasaran khutbah Jumaat adalah golongan lelaki tetapi mereka menjadi agen penting dalam memastikan isu yang dibahaskan dalam khutbah Jumaat ini direalisasikan di peringkat keluarga, masyarakat dan negara.
Istilah khutbah berasal daripada bahasa Arab yang bermaksud percakapan yang disampaikan oleh khatib. Perkataan khutbah menurut Ibn Manzur adalah percakapan yang mampu menjadi perangsang kepada pendengar. (Ibn Majah, no hadith 1126). Khutbah juga bermaksud percakapan yang ditujukan kepada orang ramai dan pendahuluan yang dibicarakan. (Ahmad al-Ayad et.al. (t.t), h. 404). Khutbah merupakan ucapan kata-kata yang baik yang disampaikan oleh seseorang dengan lidah yang fasih untuk sekumpulan manusia supaya mereka dapat menerimanya. Istilah khutbah juga memberi maksud himpunan undang-undang atau peraturan yang dapat mempengaruhi pendengar kerana di dalamnya mengandungi kesahihan fakta, pengajaran, motif dan maklumat. (Ab. Aziz Mohd Zin, 2001, h.4). Namun demikian, matlamat utama khutbah semestinya mahu memberikan bimbingan kepada manusia ke jalan yang benar. Khutbah bertindak sebagai saluran dakwah untuk membawa manusia kepada jalan Allah s.w.t selain mengarahkan pemikiran masyarakat agar terus meneguhkan akidah kepada Allah.

Khutbah juga menjadi cabang utama komunikasi dakwah yang bukan semata-mata bersifat informatif tetapi perlu memastikan mesej yang disampaikan itu membawa perubahan kepada khalayak seperti yang diinginkan oleh Islam. Jika dilihat dari kefahaman masyarakat Melayu terhadap khutbah, terdapat unsur-unsur kesucian pada khutbah di mana mesej yang dikemukakan dianggap mempunyai nilai yang tinggi untuk diterima pakai dalam kehidupan. Melalui situasi ini, khatib merupakan wadah utama dalam menentukan mesej yang disampaikan dapat meninggalkan kesan di hati para jemaah jauh lebih mudah berbanding dengan pemidato di atas pentas-pentas lain. Hubungan di antara khatib dan pendengar juga sedia terjalin melalui penghormatan yang diwujudkan atas rasa keketuaan dalam bidang keagamaan. (Muhammad Nashiruddin, 2002, h.18) 


\section{NUSANTARA; Journal for Southeast Asian Islamic Studies \\ Vol. 15, No. 2, Desember 2019}

Khutbah Jumaat pula adalah satu cara dakwah melalui lisan yang disampaikan kepada masyarakat pada setiap minggu. Pada hari berkenaan, umat Islam memenuhi masjid menunaikan solat Jumaat serta mendengar khutbah. Penyampaian khutbah dan teksnya memainkan peranan besar bagi menghasilkan khutbah yang menarik. Biarpun teks khutbah baik, namun boleh menjadi tidak menarik apabila disampaikan oleh khatib yang tidak menjiwainya, apatah lagi jika disampaikan tanpa persediaan. Justeru, ciri-ciri khutbah yang baik bergantung kepada khatib yang menyampaikan, topik yang dibicarakan, wujud unsur teguran, gaya penulisan yang menepati kaedah bahasa yang betul serta tarikan melalui persoalan yang dapat mengetuk hati pendengar berfikir.

Kajian ini dijalankan terhadap teks khutbah Jumaat negeri Johor 2017-2018 ekoran terdapat pertikaian mengenai kesahihan hadith mengenai Alqamah dalam teks khutbah Jumaat negeri Johor bertarikh17 Mac 2017, bersamaan 18 Jamadil Akhir 1438 H. Fokus utama kajian adalah kepada bentuk pemilihan tajuk khutbah, tajuk dan status hadith yang digunakan untuk menyokong tajuk khutbah. Kaedah analisis kandungan digunakan bagi menganalisa tema dan tajuk teks khutbah. Manakala kaedah takhrij hadith digunakan bagi menentukan status hadith. Analisis deskriptif mengenai tema, tajuk dan penggunaan ayat alQuran dan hadith pula diperolehi menggunakan perisian Statistical Packages for Social Sciences [SPSS 26.0]. Kajian ini dilihat penting kerana kandungan khutbah Jumaat mampu memberi impak yang positif kepada pembentukan sahsiah individu dan masyarakat. Hasil kajian ini juga boleh membantu Unit Khutbah dan Tafsir JAINJ menambahbaik mutu dan kualiti teks khutbah Jumaat negeri Johor dari semasa ke semasa.

\section{Proses Penulisan Dan Penerbitan Khutbah Jumaat Negeri Johor}

Penulisan dan penerbitan teks khutbah Jumaat negeri Johor adalah berada di bawah seliaan Bahagian Pengurusan Masjid, JAINJ. Prosedur penerbitannya adalah bermula dengan merangka tajuk di awal tahun untuk tempoh setahun. Antara faktor yang diambil kira dalam merangka tajuk adalah hari-hari kebesaran Islam, isu-isu semasa yang berlaku di negeri Johor terhadap umat Islam, isu-isu yang berterusan dan belum selesai (seperti isu akidah), isu-isu sempena sambutan hari-hari tertentu seperti dadah, alam sekitar, OKU dan sebagainya. Kemudian, sebuah bengkel penyediaan khutbah yang dianggotai oleh pegawai-pegawai daripada Jabatan Agama Islam Johor, Jabatan Mufti Johor dan Jabatan Pendidikan Johor akan diadakan bagi melihat kesesuaian tajuk yang dipilih dengan isu-isu semasa sebelum memulakan proses penulisan. Ketua Unit Khutbah \& Tafsir akan menyemak teks-teks tersebut sebelum membentangkannya di hadapan Lujnah Penyemak yang terdiri daripada Mufti, Timbalan Mufti, Qadhi Besar dan Imam Besar Negeri Johor. Setelah itu baru dicetak dan diedarkan ke masjid-masjid sekitar negeri Johor. (Mohd Hafiz Abdul Rahman, 18 Februari 2020)

Bagi tujuan pengawalan kualiti, JAINJ telah mengeluarkan satu garis panduan penulisan teks khutbah bagi tahun 2020. Penulis perlu mematuhi format asas yang ditetapkan. Antaranya; kandungan khutbah hendaklah mengandungi puji-pujian terhadap Allah yang bersesuaian dengan tajuk khutbah. Kemudian diikuti dengan syahadah, selawat, seruan takwa, kata seru "Sidang Jumaat Yang Dirahmati Allah", diikuti dengan ayat 59 Surah al-Nisa' dan diakhiri dengan ta'awwuz dan satu ayat al-Quran yang lengkap. Selain itu, garis panduan tersebut menyediakan format khas bagi hujah syarak yang digunakan dalam khutbah, termasuk panduan penggunaan ayat al-Quran, hadith, dan hujah-hujah lain seperti pandangan sahabat serta pandangan ulamak. Isi juga perlu disokong dengan hujah yang benar dan sahih. Perkara lain yang dititikbertkan dalam garis panduan ini juga adalah larangan menyentuh kedaulatan raja-raja Melayu, ajaran-ajaran yangbertentangan dengan ajaran Ahl al-Sunnah wa al-Jamah, hasutan, fitnah, unsur-unsur politik dan lain-lain perkara yang bercanggah dengan ajaran Islam.Bagi penutup khutbah, JAINJ menetapkan supaya penulis menerapkan nasihat kepada para Jemaah. Kemudian menyimpulkan kesemua isi kandungan khutbah supaya difahami umum serta merangkumkan keseluruhan hujah menggunakan ayat al-Quran yang lengkap. Ayat al-Quran tersebut perlulah menepati tajuk khutbah. (Mohd Hafiz Abdul Rahman, 18 Februari 2020) 


\section{Analisis Data dan Perbincangan}

\section{Analisis Tema Teks Khutbah Jumaat Negeri Johor 2017-2018}

Berdasarkan kepada penyelidikan yang dijalankan, teks khutbah negeri Johor sepanjang tahun 2017 dan 2018 mempunyai tiga pecahan tema yang dibahaskan dalam penulisan teks khutbah iaitu perkara yang berkaitan dengan isu semasa yang berkaitan dengan negeri Johor, pendidikan dan peristiwa penting dalam kalendar Islam atau peristiwa penting di peringkat negeri Johor.

\section{Tabel 1}

Sebaran Tema Khutbah Jumaat 2017-2018

\begin{tabular}{|c|c|c|}
\hline Tema & Kekerapan & Peratus (\%) \\
\hline Isu Semasa & 19 & 18.4 \\
\hline Pendidikan atau Pengajaran & 69 & 66.3 \\
\hline Peristiwa Penting & 16 & 15.3 \\
\hline Jumlah & 104 & 100 \\
\hline
\end{tabular}

Teks yang berkaitan dengan isu semasa ditulis berdasarkan kepada permasalahan yang berlaku dalam peringkat negeri Johor sama ada isi tersebut meliputi kes jenayah, kes pecah amanah atau isu berkaitan rasuah. Sepanjang tempoh 2017 hingga 2018 kekerapan penulisan berkaitan isu semasa adalah sebanyak 9 kali $(18.4 \%)$. Penulisan teks khutbah yang berkaitan dengan peristiwa penting yang berlaku di negeri Johor atau peristiwa penting dalam kalendar Islam seperti peristiwa awal Muharam, Istiwa' Kaabah, bulan kelahiran Nabi Muhammad S.A.W, bulan Ramadan, peristiwa Nuzul al-Quran, malam Lailatul Qadar, peristiwa Isra' Mi'raj sambutan Hari Raya Puasa, musim haji, sambutan haru guru dan sambutan bulan kemerdekaan mempunyai kekerapan sebanyak 16 kali (15.3\%) sepanjang tempoh dua tahun. Kekerapan yang terbesar adalah tema yang berkaitan dengan pendidikan atau pengajaran yang ingin disampaikan khatib sebagai peringatan kepada masyarakat Islam Johor agar sentiasa menjaga akhlak dan teladan dalam kehidupan seharian. Didikan dilihat sangat penting untuk mendidik jiwa masyarakat agar

Tabel 2

Sebaran Tajuk Mengikut Kategori

\begin{tabular}{|c|c|c|}
\hline Kategori & Kekerapan & Peratus (\%) \\
\hline Akidah & 43 & 41.3 \\
\hline Syariah & 30 & 28.8 \\
\hline Akhlak & 31 & 29.8 \\
\hline Jumlah & 104 & 100 \\
\hline
\end{tabular}

Tabel 2 menunjukkan pecahan tajuk teks khutbah Jumaat Negeri Johor dari tahun 2017 sentiasa beramal soleh dan berkelakuan baik selain menyampaikan ilmu untuk memenuhi ruang rohani masyarakat Islam daripada aspek akidah dan syariah. Kekerapan untuk tema ini adalah sebanyak 69 kali dengan jumlah peratusan $66.3 \%$.

\section{Analisis Tajuk Teks Khutbah Jumaat Negeri Johor 2017-2018}

Dalam teks khutbah Jumaat negeri Johor bagi tahun 2017 dan 2018, terdapat tiga kategori penting dijadikan platform dalam menghasilkan teks iaitu perkara melibatkan Akidah, Syariah dan Akhlak. Ketiga-tiga kategori ini menjadi asas dalam penulisan teks khutbah Jumaat di negeri Johor selain mempunyai kaitan rapat dengan tema tajuk yang memberi keutamaan kepada isu-isu semasa yang berlaku di negeri Johor, peristiwa besar dalam kalendar Islam atau peristiwa besar yang berlaku di peringkat negeri Johor dan isu-isu yang bersifat mendidik jiwa dan rohani masyarakat Islam di negeri Johor. 


\section{NUSANTARA; Journal for Southeast Asian Islamic Studies}

Vol. 15, No. 2, Desember 2019

berkaitan dengan akidah, 30 tajuk (28.8\%) berkaitan dengan syariah, dan 31 tajuk $(29.8 \%)$ lagi adalah berkaitan dengan akhlak. Secara keseluruhanya, pemilihan tajuk mengikut kategori akidah, syariah dan akhlak ini dilihat tidak seimbang penjumlahannya tetapi berdasarkan penyelidikan, tema dan tajuk khutbah mengikut kategori ini dilihat seimbang dalam menyampaikan ilmu, nasihat dan mendidik jiwa masyarakat Islam di negeri Johor seterusnya melengkapi kehendak masyarakat dalam proses menerima maklumat serta ilmu melalui penyampaian khutbah Jumaat ini. Penekanan kepada isu akidah dianggap sangat mustahak dalam memelihara pemikiran dan pegangan umat Islam kepada Allah. Melihat kepada kerapuhan akidah yang dimiliki masyarakat Islam hari ini sememangnya memberi kegusaran kepada seluruh institusi Islam termasuk JAINJ. Masyarakat Islam hari ini menghadapi cabaran besar kerana ditekan dengan pengaruh barat yang berusaha keras untuk merosakan akidah umat Islam selain terpaksa menghadapi gelombang syiah dan fahamanfahaman lain yang bertentangan dengan akidah masyarakat Islam Johor yang berpegang kepada Ahl al-Sunnah Wa al-Jamaah. Sehubungan itu, penyampaian khutbah berkaitan isu-isu akidah perlu disampaikan secara berkala agar umat Islam di Johor sentiasa peka dan dapat membezakan perkara-perkara asing yang bertentangan dengan akidah Islam. Isu akidah ini dianggap penting bagi memelihara kepercayaan umat Islam agar tidak bercabang dan menjadi punca perpecahan besar dalam kalangan umat Islam.

Berikut adalah taburan tajuk khutbah untuk kedua-dua tahun:

Tabel 3

\section{Tema Khutbah Kategori Akidah}

\begin{tabular}{|c|l|l|l|}
\hline No & \multicolumn{1}{|c|}{ Tahun } & \multicolumn{1}{|c|}{ Tema } & \multicolumn{1}{|c|}{ Subkategori } \\
\hline 1 & $06 / 01 / 2017$ & Rasulullah SAW Di Hati & Beriman Kepada Rasul \\
\hline 2 & $13 / 01 / 2017$ & Nikmat Syurga Atau Azab Neraka & Beriman Kepada Hari Akhirat \\
\hline 3 & $27 / 01 / 2017$ & Alam Kubur & Beriman Kepada Hari Akhirat \\
\hline 4 & $10 / 02 / 2017$ & Rebutlah Syurga Allah & Beriman Kepada Hari Akhirat \\
\hline 5 & $24 / 02 / 2017$ & Apabila Terjadinya Kiamat & Beriman Kepada Hari Akhirat \\
\hline 6 & $10 / 03 / 2017$ & Amalan Dihisab & Beriman Kepada Hari Akhirat \\
\hline 7 & $24 / 03 / 2017$ & Hari Kebangkitan & Beriman Kepada Hari Akhirat \\
\hline 8 & $14 / 04 / 2017$ & Tiupan Sangkakala & Beriman Kepada Rasul \\
\hline 9 & $21 / 04 / 2017$ & Hikmah Israk Dan Mikraj \\
\hline 10 & $26 / 05 / 2017$ & Tuntutan Ramadhan & Beriman Kepada Allah \\
\hline 11 & $02 / 06 / 2017$ & Al-Quran Kalam Allah & Beriman Kepada Kitab \\
\hline 12 & $16 / 06 / 2017$ & Lailatul Qadar & Beriman Kepada Allah \\
\hline 13 & $23 / 06 / 2017$ & Bahagia Dunia, Bahagia Akhirat & Beriman Kepada Qadha' Dan Qadar \\
\hline 14 & $30 / 06 / 2017$ & Hindarilah Su'ul Khatimah & Beriman Kepada Qadha' Dan Qadar \\
\hline 15 & $21 / 07 / 2017$ & Hidupkan Sunnah Rasulullah & Beriman Kepada Rasul \\
\hline 16 & $01 / 09 / 2017$ & Nikmat Hidayah & Beriman Kepada Allah \\
\hline 17 & $08 / 09 / 2017$ & Mahsyar Yang Pasti Berlaku & Beriman Kepada Hari Akhirat \\
\hline 18 & $15 / 09 / 2017$ & Hijrah Yang Sebenar & Beriman Kepada Rasul \\
\hline 19 & $22 / 09 / 2017$ & Persiapan Menuju Akhirat & Beriman Kepada Hari Akhirat \\
\hline 20 & $06 / 10 / 2017$ & Berpegang Kepada Ahli al-Sunnah & Beriman Kepada Rasul \\
\hline 21 & $13 / 10 / 2017$ & Hidup Mati Itu Ketentuan Allah & Beriman Kepada Qadha' Dan Qadar \\
\hline 22 & $27 / 10 / 2017$ & Buku Catatan Amal Kali Kedua Dibuka & Beriman Kepada Qadha' Dan Qadar \\
\hline 23 & $10 / 11 / 2017$ & Azab Neraka & Beriman Kepada Hari Akhirat \\
\hline 24 & $22 / 12 / 2017$ & Redha Allah Atau Redha Manusia & Beriman Kepada Allah \\
\hline 25 & $05 / 01 / 2018$ & Disemarakkan Syiar Islam Di Muka Bumi & Beriman Kepada Allah \\
\hline 26 & $19 / 01 / 2018$ & Gerhana Bulan [Khutbah Khas] & Beriman Kepada Allah \\
\hline 27 & $09 / 20 / 2018$ & Akhir Hayat Laa Ilaaha Illallah & Beriman Kepada Allah \\
\hline 28 & $09 / 02 / 2018$ & Nikmat Dunia Yang Sementara & Beriman Kepada Hari Akhirat \\
\hline 29 & $16 / 03 / 2018$ & Penghayatan Akidah & Beriman Kepada Allah \\
\hline & & & \\
\hline
\end{tabular}




\begin{tabular}{|l|l|l|l|}
\hline 30 & $23 / 03 / 2018$ & Kehidupan Dunia Adalah Ujian & Beriman Kepada Qadha' Dan Qadar \\
\hline 31 & $04 / 05 / 2018$ & Sifat 20 bagi Allah SWT & Beriman Kepada Allah \\
\hline 32 & $08 / 06 / 2018$ & Kedatangan Malaikat Izrail & Beriman Kepada Malaikat \\
\hline 33 & $29 / 06 / 2018$ & Wajah Hari Kebangkitan & Beriman Kepada Hari Akhirat \\
\hline 34 & $13 / 07 / 2018$ & Janji Allah Itu Benar & Beriman Kepada Allah \\
\hline 35 & $24 / 08 / 2018$ & Qadha' Dan Qadar Allah & Beriman Kepada Qadha' Dan Qadar \\
\hline 36 & $31 / 08 / 2018$ & Gerhana Bulan- Khutbah Khas & Beriman Kepada Allah \\
\hline 37 & $14 / 09 / 2018$ & Pelihara Hati & Beriman Kepada Allah \\
\hline 38 & $05 / 10 / 2018$ & Jalan Menuju Syurga & Beriman Kepada Allah \\
\hline 39 & $19 / 10 / 2018$ & Usaha Dan Tawakal & Beriman Kepada Qadha' Dan Qadar \\
\hline 40 & $02 / 11 / 2018$ & Akidah al-'Asyairah dan al-Maturidiah & Beriman Kepada Rasul \\
\hline 41 & $09 / 11 / 2018$ & Akidah Kukuh, Diri Teguh & Beriman Kepada Allah \\
\hline 42 & $16 / 11 / 2018$ & Kasih Akan Rasulullah SAW & Beriman Kepada Rasul \\
\hline 43 & $30 / 11 / 2018$ & Berpegang Teguh Dengan Islam & Beriman Kepada Allah \\
\hline
\end{tabular}

Tabel 3 pula menunjukkan kekerapan dan peratusan teks khutbah Jumaat Negeri Johor 2017-2018 bagi tajuk akidah. Keutamaan yang diberi ialah kepada tajuk-tajuk yang berkaitan dengan konsep beriman kepada Allah, iaitu sebanyak 15 tajuk (34.9\%). Kedua, konsep beriman kepada Hari Akhirat, iaitu sebanyak 12 tajuk $(27.9 \%)$. Kemudian beriman kepada Rasul serta Qadha' dan Qadar, dengan masing-masing sebanyak 7 tajuk (16.3\%). Manakala bagi subkategori beriman kepada Malaikat dan Kitab, masing-masing adalah 1 tajuk (16.3\%). Penekanan tajuk akidah dilihat sebagai satu bentuk ilmu yang disampaikan kepada masyarakat dalam memastikan kepercayaan masyarakat kepada ajaran Islam tidak goyah. Pengukuhan akidah sangat penting dalam memastikan ajaran Islam tidak dicemari oleh sebarang anasir luar selain berperanan sebagai tulang belakang untuk membetuk kekuatan perpaduan dalam kalangan masyarakat Islam di Johor.

Tabel 4

\section{Subkategori Akidah}

\begin{tabular}{|l|c|c|}
\hline \multicolumn{1}{|c|}{ Kategori } & Jumlah & Persen (\%) \\
\hline Beriman Kepada Allah & 15 & 34.9 \\
\hline Beriman Kepada Malaikat & 1 & 2.3 \\
\hline Beriman Kepada Kitab & 1 & 2.3 \\
\hline Beriman Kepada Rasul & 7 & 16.3 \\
\hline Beriman Kepada Hari Akhirat & 12 & 27.9 \\
\hline Beriman Kepada Qadha' Dan Qadar & 7 & 16.3 \\
\hline \multicolumn{1}{|c|}{ Jumlah } & 43 & 100 \\
\hline
\end{tabular}

Tabel 5

Sebaran Tajuk Khutbah Bagi Kategori Syariah

\begin{tabular}{|c|l|l|l|}
\hline No & \multicolumn{1}{|c|}{ Tahun } & \multicolumn{1}{|c|}{ Tema } & Subkategori \\
\hline 1 & $03 / 02 / 2017$ & Azab Menanti Pengamal Riba & Muamalat \\
\hline 2 & $03 / 03 / 2017$ & Bertambah Dengan Sebab Bersedekah & Muamalat \\
\hline 3 & $07 / 04 / 2017$ & Keagungan Bulan Haram & Ibadah \\
\hline 4 & $05 / 05 / 2017$ & Menghidupkan Bulan Syaaban & Ibadah \\
\hline 5 & $19 / 05 / 2017$ & Perbanyakkan Solat Sunat & Ibadah \\
\hline 6 & $09 / 06 / 2017$ & Keberkatan Dengan Berzakat & Ibadah \\
\hline 7 & $03 / 11 / 2017$ & Keretakan Keluarga & Munakahat \\
\hline 8 & $24 / 11 / 2017$ & Bahaya Fitnah & Munakahat \\
\hline 9 & $08 / 12 / 2017$ & Harta Milik Allah & Ibadah \\
\hline 10 & $26 / 01 / 2018$ & Solat Penghubung kpd Allah dan Pendinding dari Maksiat & Ibadah \\
\hline 11 & $23 / 02 / 2018$ & Maqasid Syar'iyyah Dalam Kehidupan & Ibadah \\
\hline
\end{tabular}


Vol. 15, No. 2, Desember 2019

\begin{tabular}{|l|l|l|l|}
\hline 12 & $02 / 03 / 2018$ & Apabila Masjid Tiada Pengimarahan & Ibadah \\
\hline 13 & $09 / 03 / 2018$ & Perceraian Dan Kesan-kesannya & Muamalat \\
\hline 14 & $06 / 04 / 2018$ & Syariat Islam Membangunkan Negara Maju & Kenegeraan \\
\hline 15 & $13 / 04 / 2018$ & Pengajaran Israk Mikraj & Ibadah \\
\hline 16 & $27 / 04 / 2018$ & Awlawiyyat [Keutamaan] Dalam Kehidupan & Ibadah \\
\hline 17 & $18 / 05 / 2018$ & Hikmah Ramadhan & Ibadah \\
\hline 18 & $25 / 05 / 2018$ & Istiwa' Kaabah & Ibadah \\
\hline 19 & $01 / 06 / 2018$ & Nuzul Quran & Ibadah \\
\hline 20 & $22 / 06 / 2018$ & Persediaan Hadapi Munkar Nakir & Ibadah \\
\hline 21 & $06 / 07 / 2018$ & Bersegera Mendirikan Solat Subuh & Ibadah \\
\hline 22 & $20 / 07 / 2018$ & Halal Itu Jelas & Muamalat \\
\hline 23 & $27 / 07 / 2018$ & Wasiat Dalam Islam & Muamalat \\
\hline 24 & $21 / 09 / 2018$ & Tiada Rasa Nikmat Ibadah & Ibadah \\
\hline 25 & $28 / 09 / 2018$ & Sakinah, Mawaddah, Rahmah Dalam Keluarga & Munakahat \\
\hline 26 & $12 / 10 / 2018$ & Harta Dunia Yang Tidak Pernah Cukup & Ibadah \\
\hline 27 & $07 / 12 / 2018$ & Berzakat, Berwakaf dan Berinfaq & Ibadah \\
\hline 28 & $14 / 12 / 2018$ & Adab Menghadiri Solat & Ibadah \\
\hline 29 & $21 / 12 / 2018$ & Kasih Kepada Ibubapa & Munakahat \\
\hline 30 & $28 / 12 / 2018$ & Pelihara Alam Ciptaan Allah & Ibadah \\
\hline & & & \\
\hline
\end{tabular}

Tabel 3.4 menunjukkan perincian tajuk khutbah bagi kategori Syariah. Tajuk-tajuk yang ditulis adalah berkaitan dengan lima subkategori, seperti di dalam tabel 1.5; iaitu Ibadah; 20 tajuk (66.7\%), muamalat; 5 tajuk (16.6\%), munakahat; 4 tajuk $(13.3 \%)$ dan kenegaraan 1 tajuk (3.3\%). Hasil kajian mendapati, topik-topik berkaitan ibadah lebih menjadi keutamaan penulis teks khutbah Negeri Johor 2017-2018 berbanding muamalat, munakahat dan kenegaraan. Pemilihan tajuk yang berkaitan isu munakahat dan muamalat ini adalah berdasarkan kepada keadaan semasa yang berlaku di negeri Johor. Johor mencatatkan jumlah penceraian ketiga tertinggi di Malaysia selepas Selangor dan Sabah bagi tahun 2017 dan
2018. (Berita Harian, 4 Mac, 2019) Sehubungan itu, tajuk khutbah berkaitan isu ini diberi penekanan oleh Lajnah Pengurusan Masjid JAINJ agar dapat memberi peringatan kepada masyarakat Islam di Johor tentang kepentingan menjaga institusi kekeluargaan agar tidak mudah roboh dibadai ombak atau dicemari dengan akhlak negatif sehingga merosakan hubungan kekeluargaan yang dibina. Isu muamalat diberi penekanan dengan tujuan memberi ilmu dan maklumat kepada masyarakat berkenaan isu wakaf, zakat, amalan sedekah, riba dan pengurusan harta mengikut syariat Islam.

Tabel 6

Subkategori Syariah

\begin{tabular}{|l|c|c|}
\hline \multicolumn{1}{|c|}{ Bidang } & Kekerapan & Peratus (\%) \\
\hline Ibadah & 20 & 66.7 \\
\hline Muamalat & 5 & 16.6 \\
\hline Munakahat & 4 & 13.3 \\
\hline Kenegaraan & 1 & 3.3 \\
\hline Jumlah & 30 & 100 \\
\hline
\end{tabular}

\section{Tabel 7}

Taburan Tajuk Khutbah Bagi Kategori Akhlak

\begin{tabular}{|l|l|l|l|}
\hline Bil. & \multicolumn{1}{|c|}{ Tarikh } & \multicolumn{1}{c|}{ Tajuk } & \multicolumn{1}{c|}{ Subkategori } \\
\hline 1 & $20 / 01 / 2017$ & Rasa Takut dan Mengharap & Akhlak Terhadap Allah \\
\hline 2 & $17 / 02 / 2017$ & Dimanakah Ikhlasku & Akhlak Terhadap Allah \\
\hline 3 & $17 / 03 / 2017$ & Kasih Kepada Orang Tua & Akhlak Terhadap Manusia \\
\hline
\end{tabular}


Munirah binti Zakaria, dkk: Teks Khuthbah Jumaat Negerei Johor...

\begin{tabular}{|l|l|l|l|}
\hline 4 & $28 / 04 / 2017$ & Apabila Hati Keras & Akhlak Terhadap Allah \\
\hline 5 & $12 / 05 / 2017$ & Didiklah Anak & Akhlak Terhadap Manusia \\
\hline 6 & $07 / 07 / 2017$ & Perbaiki Akhlak & Akhlak Terhadap Manusia \\
\hline 7 & $14 / 07 / 2017$ & Sabar Dalam Ujian & Akhlak Terhadap Allah \\
\hline 8 & $28 / 07 / 2017$ & Anak Anugerah Allah & Akhlak Terhadap Manusia \\
\hline 9 & $04 / 08 / 2017$ & Apabila Sifat Malu Telah Hilang & Akhlak Terhadap Manusia \\
\hline 10 & $11 / 08 / 2017$ & Tarbiah Rabbani Anak-anak & Akhlak Terhadap Manusia \\
\hline 11 & $18 / 08 / 2017$ & Bahaya Lidah & Akhlak Terhadap Manusia \\
\hline 12 & $25 / 08 / 2017$ & Hargai Nikmat Allah & Akhlak Terhadap Allah \\
\hline 13 & $29 / 09 / 2017$ & Punca Perpecahan Mesti Dielakkan & Akhlak Terhadap Manusia \\
\hline 14 & $20 / 10 / 2017$ & Bersama Cegah Maksiat & Akhlak Terhadap Manusia \\
\hline 15 & $17 / 11 / 2017$ & Mencintai Ilmu & Akhlak Terhadap Allah \\
\hline 16 & $01 / 12 / 2017$ & Menghayati Perjuangan Rasulullah SAW & Akhlak Terhadap Allah \\
\hline 17 & $15 / 12 / 2017$ & Muhasabah Diri & Akhlak Terhadap Allah \\
\hline 18 & $29 / 12 / 2017$ & Islam Menitikberatkan Kesihatan & Akhlak Terhadap Alam \\
\hline 19 & $12 / 01 / 2018$ & Amanah Satu Tanggungjawab & Akhlak Terhadap Allah \\
\hline 20 & $19 / 01 / 2018$ & Hidupkan Usaha Dakwah & Akhlak Terhadap Manusia \\
\hline 21 & $16 / 02 / 2018$ & Apabila Anak Menjadi Tuan & Akhlak Terhadap Manusia \\
\hline 22 & $30 / 03 / 2018$ & Akhlak Runtuh Negara Lumpuh & Akhlak Terhadap Manusia \\
\hline 23 & $20 / 04 / 2018$ & Gejala Sosial Tiada, Masyarakat Sejahtera & Akhlak Terhadap Manusia \\
\hline 24 & $11 / 05 / 2018$ & Guru Mukmin Pemangkin Generasi Muda & Akhlak Terhadap Manusia \\
\hline 25 & $15 / 06 / 2018$ & Keadilan Islam & Akhlak Terhadap Manusia \\
\hline 26 & $03 / 08 / 2018$ & Selidik Dahulu & Akhlak Terhadap Manusia \\
\hline 27 & $10 / 08 / 2018$ & Mengejar Kebaikan & Akhlak Terhadap Allah \\
\hline 28 & $17 / 08 / 2018$ & Menyambut Panggilan Haji & Akhlak Terhadap Allah \\
\hline 29 & $07 / 09 / 2018$ & Ibrah Peristiwa Hijrah & Akhlak Terhadap Allah \\
\hline 30 & $26 / 10 / 2018$ & Bangkitlah Wahai Umat Islam & Akhlak Terhadap Manusia \\
\hline 31 & $23 / 11 / 2018$ & Syukur Atau Kufur & Akhlak Terhadap Allah \\
\hline & & & \\
\hline
\end{tabular}

Tabel 6 menunjukkan perincian tajuk khutbah Negeri Johor 2017-2018 bagi kategori akhlak. Tajuk-tajuk yang ditulis adalah berkaitan dengan tiga subkategori, seperti di dalam tabel 7; iaitu akhlak terhadap Allah; 13 tajuk (42\%), akhlak terhadap manusia; 17 tajuk (54.8\%), dan akhlak terhadap alam; 1 tajuk (3.2\%). Penulis mendapati bahawa pada kedua-dua tahun tersebut, kecenderungan pemilihan tajuk akhlak adalah kepada akhlak terhadap manusia dan
Allah. Manakala akhlak terhadap alam hanya sedikit dikupas. Penekenan akhlak manusia sesama manusia diberi penekanan pada isu-isu semasa yang melibatkan jenayah di negeri Johor pada tahun 2017 agak tinggi dengan kadar 11, 307 kes dan 10, 339 kes pada tahun 2018. Isu-isu jenayah ini melibatkan pembunuhan, kecurian harta benda, penagihan dadah dan khianat. (Berita Harian, 2 Jan, 2019)

Tabel 8

Subkategori Akhlak

\begin{tabular}{|c|c|c|}
\hline \multicolumn{1}{|c|}{ Bidang } & Kekerapan & Peratus (\%) \\
\hline Akhlak Terhadap Allah & 13 & 42 \\
\hline Akhlak Terhadap Manusia & 17 & 54.8 \\
\hline Akhlak Terhadap Alam & 1 & 3.2 \\
\hline Jumlah & 31 & 100 \\
\hline
\end{tabular}

\section{Analisa Penggunaan Hadith Dalam Teks Khutbah Jumaat Negeri Johor 2017-2018}

Penggunaan dalil hadith dalam penulisan teks khutbah Jumaat membawa kepada pengukuhan mesej yang ingin disampaikan. Analisis data dalam topik ini membincangkan penggunaan hadith sebagai dalil sokongan dalam teks khutbah Jumaat di negeri Johor pada tahun 2017 dan 2018. Berikut adalah tabel mengenai 
taburan bilangan hadith yang dimasukkan dalam teks khutbah Jumaat di negeri Johor:

Tabel 9

Sebaran Bilangan Hadith Dalam Teks Khutbah Negeri Johor 2017-2018

\begin{tabular}{cccc}
\hline No & Masalah & Jumlah & Prosentase \\
\hline 1 & Teks khutbah tanpa penggunaan hadith & 28 & 26.9 \\
2 & Teks khutbah dengan 1 hadith & 31 & 29.8 \\
3 & Teks khutbah dengan 2 hadith & 25 & 24.0 \\
4 & Teks khutbah dengan 3 hadith & 15 & 14.4 \\
5 & Teks khutbah dengan 4 hadith & 4 & 3.8 \\
6 & Teks khutbah dengan 5 hadith & 1 & 1.1 \\
& Jumlah & 104 & 100 \\
\hline
\end{tabular}

Sepanjang tahun 2017 hingga 2018, jumlah teks khutbah Jumaat di negeri Johor ialah sebanyak 104. Dari jumlah berkenaan, hasil kajian mendapati terdapat 28 teks khutbah $(26.9 \%)$ yang tidak mengunakan hadith dalam teks khutbah manakala baki 76 teks khutbah (73.1\%) menggunakan hadith dalam teks khutbah dengan pelbagai bilangan hadith yang dimuatkan dalam sebuah teks khutbah Jumaat pada tahun 2017 hingga 2018. Hal ini menunjukkan teks khutbah Jumaat terbitan Majlis Agama Islam Johor (MAIJ) memberi penekanan terhadap penggunaan hadith sebagai hujah selain dari penggunaan dalil dari alquran dalam teks khutbah Jumaat di negeri Johor.

Kajian ini juga mengkaji mengenai riwayat hadith yang terdapat di dalam teks khutbah Jumaat. Riwayat bagi hadith turut berkepentingan dalam penentuan status hadith. Berikut adalah tabel mengenai taburan riwayat hadith yang terdapat di dalam teks khutbah Jumaat di negeri Johor:

\section{Tabel 10}

Taburan Riwayat Hadith Dalam Teks Khutbah Negeri Johor 2017-2018

\begin{tabular}{cccc}
\hline No & Periwayat & Jumlah & Prosentase \\
\hline 1 & Riwayat Bukhari & 30 & 20.4 \\
2 & Riwayat Muslim & 18 & 12.2 \\
3 & Riwayat Tirmizi & 23 & 15.7 \\
4 & Riwayat Ahmad & 22 & 15.0 \\
5 & Riwayat Ibnu Majah & 11 & 7.5 \\
6 & Riwayat Nasai & 1 & 0.7 \\
7 & Lain-lain & 9 & 6.1 \\
8 & Tidak dinyatakan & 33 & 22.4 \\
& Jumlah & 147 & 100 \\
\hline
\end{tabular}

Berdasarkan tabel di atas, pengkaji mendapati penulisan teks khutbah Jumaat yang dikaji ini menyandarkan hadith dari perawi yang masyhur iaitu Imam Bukhari, Imam Muslim, Imam Tirmizi, Imam Ahmad, Imam Ibnu Majah dan Imam Nasai. Hadith Riwayat Bukhari ditulis sebanyak 30 hadith (20.4\%) dan Muslim sebanyak 18 hadith $(12.2 \%)$. Selain itu, terdapat sembilan hadith $(6.1 \%)$ yang diambil dari riwayat lain seperti Ibnu Hibban, al-Tabarani dan al-Baihaqi. Terdapat juga 33 hadith $(22.4 \%)$ yang tidak dinyatakan riwayat di dalam teks khutbah Jumaat yang dikaji. Hal ini memberi kesan dalam memastikan kesahihan dan status hadith yang digunakan sebagai sandaran.

Kajian ini turut memfokuskan kepada status hadith yang dimuatkan di dalam teks khutbah Jumaat. Status bagi hadith penting dalam menentukan hadith tersebut sama ada diterima atau sebaliknya. Berikut adalah tabel mengenai taburan status hadith yang diguna pakai di dalam teks khutbah Jumaat di negeri Johor: 
Tabel 11

Taburan Status Hadith Dalam Teks Khutbah Negeri Johor 2017-2018

\begin{tabular}{cccc}
\hline No & Periwayat & Jumlah & Prosentase \\
\hline 1 & Status hadith sahih & 87 & 59.2 \\
2 & Status hadith hasan & 31 & 21.1 \\
3 & Status hadith dhaif & 4 & 2.7 \\
4 & Lain-lain & 25 & 17.0 \\
& Jumlah & 147 & 100 \\
\hline
\end{tabular}

Jumlah hadith yang ditulis di dalam teks khutbah Jumaat negeri Johor ialah 147. Berdasarkan dapatan kajian, terdapat 87 hadith $(59.2 \%)$ yang berstatus sahih dimuatkan sebagai sokongan dalam teks khutbah Jumaat. Hadith yang berstatus hasan pula ialah 31 hadith (21.1\%). Penggunaan hadith yang berstatus sahih dan hasan menunjukkan kekerapan yang tinggi berbanding yang lain.

Walaupun jumlah hadith yang berstatus sahih dan hasan menunjukkan kekerapan yang lebih besar, terdapat kewujudan hadith dhaif sebanyak 4 hadith $(2.7 \%)$. Antara ciri hadith dhaif ialah sanad yang tidak bersambung atau perawi yang dipertikaikan di dalam sanad (Mohd. Norzi et. al 2017). Namun, terdapat pendapat yang membolehkan untuk beramal dengan hadith dhaif yang berkaitan dengan kelebihan beramal (Mufti Wilayah Persekutuan Kuala Lumpur 2016). Contoh hadith dhaif yang terdapat di dalam teks khutbah Jumaat ialah seperti berikut:

a) Hadith ini ditulis dalam teks Khutbah Jumaat Negeri Johor pada 17 Mac 2017 bersamaan 18 Jamadil Akhir 1438. Kajian ini mendapati bahawa terdapat hadith yang tidak ditemui sumber diletakkan di dalam teks khutbah Jumaat. Antara faktor yang menyebabkan kewujudan kategori ini ialah penulisan teks beserta hadith yang ditulis terjemahan dalam Bahasa Melayu sahaja dan hadith tidak diletakkan riwayat sebagai rujukan. Contoh hadith tersebut yang terdapat di dalam teks khutbah Jumaat ialah seperti berikut:

Maksudnya:

"Ada seorang pemuda bernama alqamah di zaman Rasulullah SAW, pemuda ini rajin ibadah dan banyak bersedekah, tiba-tiba dia sakit dan sangat berat sakitnya, maka isterinya menyuruh orang memanggil Rasulullah SAW dan memberitahu baginda SAW yang suaminya berada dalam keadaan nazak. Nabi SAW menghantar Ammar Suhaib dan juga Bilal sambil berpesan: Pergilah menemuinya dan ajarkanlah kalimah syahadah kepada-Nya. Utusan Rasulullah SAW tersebut pergi ke kampung Alqamah ketika sampai mereka langsung kepadanya dan menuntutnya supaya membaca Laa Ilaaha Illa Allah, tetapi lidahnya bagaikan terkunci tidak dapat mengucapkannya, ketika para sahabat berasa bahawa Alqamah pasti akan mati, mereka menyuruh Bilal supaya pergi memberitahu hal itu kepada Rasulullah SAW. Rasulullah SAW langsung bertanya: Apakah dia masih mempunyai bapa dan ibu? Jawabnya bapanya telah meninggal, sedang ibunya masih hidup tetapi terlampau tua. Rasulullah SAW bersabda kepada Bilal: Ya Bilal, pergilah kepada ibunya dan sampaikan kepadanya salamku, dan katakana kepadanya: Jika engkau dapat berjalan pergi kepada Rasulullah SAW dan jika tidak dapat maka Rasulullah SAW akan datang ke sini. Jawab ibunya sayalah yang lebih layak pergi kepada Nabi SAW. Lalu dia mengambil tongkat dan berjalanhingga masuk ke rumah Nabi SAW dan sesudah memberi salam, dia duduk di hadapan Nabi SAW. Maka Nabi SAW bertanya: beritakan yang benar-benar kepadaku, jika engkau dusta kepadaku, nescaya akan turun wahyu memberitahu kepadaku: Bagaimana keadaan Alqamah? Jawabnya: Alqamah rajin sembahyang, puasa dan bersedekah sebanyak-banyaknya sehingga tidak diketahui berapa banyaknya. Nabi SAW bertanya: Lalu bagaimana hubunganmu 


\section{NUSANTARA; Journal for Southeast Asian Islamic Studies}

Vol. 15, No. 2, Desember 2019

dengan dia? Jawabnya: Saya murka kepadanya. Ditanya: Mengapa? Kerana dia mengutamakan isterinya lebih daripadaku, dan menurut isterinya dan menentangku. Maka Rasulullah bersabda: Murka ibunya itu yang mengunci (menutup) lidahnya untuk mengucap Laa Ilaaha Illa Allah. Kemudian Nabi SAW menyuruh Bilal supaya mengumpulkan kayu sebanyakbanyaknya untuk membakar Alqamah dengan api itu. Ibunya bertanya: Ya Rasulullah, puteraku, buah hatiku akan engkau bakar dengan api di depanku, bagaimana akan dapat menerima hatiku. Rasulullah SAW bersabda: Wahai ibu Alqamah, siksa Allah lebih berat dan kekal, kerana itu jika engkau ingin Allah mengampunkan dosa anakmu, maka relakanlah dia (engkau harus redha padanya), demi Allah yang jiwaku di tangannya, tidak akan berguna sembahyangnya, sedekahnya selama engkau murka kepadanya. Lalu ibu mengangkat kedua tangannya seraya berkata: Ya Rasulullah saya mempersaksikan Allah di langit dan engkau ya Rasulullah dan siapa yang hadir di tempat ini bahawa saya telah redha padanya Alqamah. Maka langsung Rasulullah SAW menyuruh Bilal pergi melihat keadaannya, apakah sudah mengucap Laa Ilaaha Illa Allah atau tidak, khuatir kalau-kalau ibunya mengucapkan itu hanya kerana malu pada Rasulullah dan tidak dari hatinya. Maka ketika Bilal sampai di pintu rumahnya, tiba-tiba terdengar suaranya membaca Laa Ilaaha Illah Allah lalu Bilal masuk dan berkata: "Wahai kalian, sesungguhnya murka ibunya itu yang menutup lidahnya untuk mengucapkan syahadah, dan redhanya kini telah melepaskan lidahnya, maka meninggal dunia Alqamah pada hari itu, lalu datanglah Rasulullah SAW dan menyuruh supaya segera dimandikan dan dikafankan lalu disembahyangkan oleh Nabi SAW. Dan sesudah di kubur, Nabi SAW berdiri di atas tepi kubur, sambil berkata: Wahai sahabat muhajir dan ansar, siapa yang mengutamakan isterinya daripada ibunya maka dia terkena kutukan (laknat) Allah dan tidak diterima daripadanya ibadah fardhu dan sunatnya."

Kisah ini tidak sahih menurut Imam Ibnu al Jauzi. Kisah ini dilaporkan daripada jalur Fa'id yang dituduh berdusta. Menurut Ibnu Hajar, beliau tidak menemui matan yang menyebut nama Alqamah dalam kisah berkenaan. Antara sumber lain yang menyebut kisah berkenaan ialah al-Dhuafa al-Kabir oleh al-Uqaili, al-Maudhu'at oleh Ibn al-Jauzi, Masawi al-Akhlaq oleh alKharaiti, Syu'ab al-Iman oleh al-Baihaqi, Dalail alNubuwwah oleh al-Baihaqi dan al-Tadwin fi Tarikh Qazwin oleh al-Qazwini (Mufti Wilayah Persekutuan Kuala Lumpur 2018). Kisah Alqamah yang tidak dapat dipastikan asalnya wajar digantikan dengan hadith yang sahih oleh penulis teks khutbah Jumaat. Khutbah Jumaat patut dijadikan medan untuk menyampaikan dakwah dengan menyatakan hadith yang sahih. Oleh yang demikian, rujukan kandungan khutbah Jumaat terutama dalam dalil yang dimuatkan di dalam teks khutbah Jumaat perlu dipastikan terlebih dahulu.

b) Hadith ini ditulis dalam teks Khutbah Jumaat Negeri Johor pada 5 Mei 2017 bersamaan 8 Syaaban $1439 \mathrm{H}$.

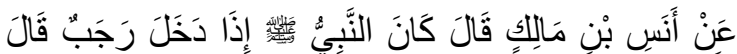

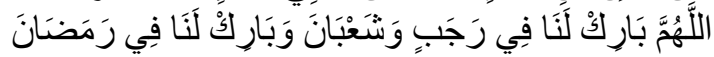

Maksudnya:

"Daripada Anas bin Malik RA berkata: Adalah Rasulullah SAW apabila datangnya bulan Rejab, Rasulullah membaca doa (maksudnya) berkatilah kami dalam Rejab dan Syaban dan berkatilah kami dalam Ramadan.” (Riwayat Ahmad)

c) Hadith ini ditulis dalam teks Khutbah Jumaat Negeri Johor pada 6 Oktober 2017 bersamaan 16 Muharram $1439 \mathrm{H}$.

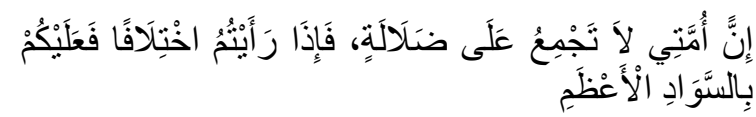

Maksudnya:

"Umatku tidak akan bersepakat di dalam perkara yang sesat, jika kamu melihat mereka itu berselisihan hendaklah kamu berpegang kepada kelompok jemaah yang tersebar.’( Riwayat Ibnu Majah) 
d) Hadith ini ditulis dalam teks Khutbah Jumaat Negeri Johor pada 2 Mac 2018 bersamaan 14 Jamadil Akhir 1439H.

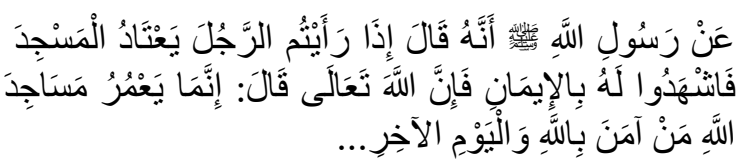

Maksudnya:

"Dari Rasulullah SAW bahawasanya Baginda bersabda (maksudnya): Apabila kamu melihat seorang lelaki sentiasa mengunjungi masjid, maka saksikanlah yang dia adalah seorang yang beriman. Maka Allah berfirman (maksudnya): Sesungguhnya yang (layak) memakmurkan (menghidupkan) masjid-masjid Allah itu, ialah orang yang beriman kepada Allah dan hari Akhirat ..." (Riwayat Ahmad)

\section{Kesimpulan}

Khutbah Jumaat dilihat sebagai medium produktif untuk mendidik generasi muda selain menyampaikan kesahihan maklumat kepada masyarakat Islam. Pemilihan tajuk khutbah adalah penting bagi memastikan pendengar terdidik jiwanya selain menjadi panduan dalam kehidupan seharian. Bagi mendapatkan mutu penulisan yang lebih berkualiti beberapa perkara harus ditekankan antaranya adalah dengan membuat penambahbaikan dalam penulisan teks khutbah Jumaat Negeri Johor dengan menyeimbangkan tajuk-tajuk bagi ketiga-tiga kategori. Contohnya bagi kategori akidah, penekanan harus turut sama diberi kepada aspek beriman kepada malaikat, kitab, rasul serta qadha' dan qadar, bukan sahaja kepada aspek beriman kepada Allah dan Hari akhirat. Ini kerana aspek-aspek tersebut adalah amat penting dalam proses pembinaan dan pemerkasaan akidah Muslim. Begitu juga bagi kategori Syariah, aspek muamalat, munakahat dan kenegaraan perlu diberi perhatian sepetimana aspek ibadah dalam penulisan teks khutbah Jumaat negeri Johor. Ianya penting bagi membudayakan konsep celik Syariah kepada masyarakat umum. Bagi kategori akhlak pula, penekanan juga harus diberi kepada aspek akhlak terhadap alam sepertimana akhlak terhadap Allah dan manusia memandangkan ketiga-tiganya merupakan skop akhlak dalam Islam.
Penggunaan hadith pula sangat penting dalam mengukuhkan penyampaian tajuk khutbah Jumaat. Hal ini kerana hadith bertindak sebagai penguat kepada hujah atau dalil penting bagi mengesahkan fakta yang terdapat dalam teks khutbah. Sehubungan itu, penyelidik melihat penggunaan hadith sahih dan berautoriti sangat mustahak dalam penulisan khutbah Jumaat berbanding hadith dhaif. Penggunaan hadith dhaif boleh menimbulkan keraguan kepada pendengar, Walaupun ianya tidak salah untuk diketengahkan sebagai satu bentuk amalan positif dalam kalangan masyarakat, namun mendidik masyarakat mengutamakan hadith sahih sebagai sumber rujukan akan melahirkan masyarakat yang lebih berhati-hati dalam berhujah. 


\section{NUSANTARA; Journal for Southeast Asian Islamic Studies}

Vol. 15, No. 2, Desember 2019

\section{DAFTAR PUSTAKA}

Abdullah Bin Mat dan Muhyidin Bin Hj Aziz (2003), Konsep dan Falsafah Masjid, Selangor: Intel Multimedia and Publication

Berita Harian, Kadar Indeks Jenayah Menurun, 2 Januari 2019

Ibn Majah, Sunan Ibn Majah, Bab Ma Ja fi Istiqbal al-Imam Wahuwa Yakhtub, no hadith 1126

Ibn Manzur (1990), Lisan al-'Arab, j.1 Beirut: Dar al-Fikr

Mohd Faizal Bin Mat Nasan (2002), "Isu-Isu Hukum Dalam Khutbah Jumaat di Wilayah Persekutuan Kuala Lumpur, Satu Kajian Dari Tahun 1995-2000”, Universiti Malaya Kuala Lumpur

Mohd Norzi Nasir, Badrul Hisham Mahadzir, Siti Murshidah Mohd Zin. (2016). Kefahaman Terhadap Hadis Dhaif Yang Masyhur di Kalangan Mahasiswa Jabatan al-Quran dan al-Sunnah FPPI, KUIS. $2^{\text {nd }}$ International Muzakarah \& Mu'tamar On Hadith (IMAM2017)

Mufti Wilayah Persekutuan Kuala Lumpur. (2016). Ringkasan Mengenai Pembentangan Kertas Kerja Seminar "Home of Hadith" (Pengamalan Hadith Dhoif. Irsyad al-Hadith, 68. From https://muftiwp.gov.my/en/artikel/irsya d-al-hadith/1131-irsyad-al-hadith-siri-ke68-ringkasan-mengenai-pembentangankertas-kerja-seminar-home-of-hadithpengamalan-hadith-dhoif.

Muhammad Nashiruddin (2002), Perbahasan Mengenai Khutbah Jumaat, Johor Bahru: Perniagaan Jahabersa

Muti Wilayah Persekutuan Kuala Lumpur. (2018). Hukum Menempatkan Ibubapa di Rumah Orang Tua. Bayyan Linnas, 127. From https://muftiwp.gov.my/artikel/bayanlinnas/2294-bayan-linnas-siri-ke-127hukum-menempatkan-ibubapa-di-rumahorang-tua

Namri Sidek, Tiga Negeri Yang Mencatatkan Kadar Penceraian Tertinggi di Malaysia, 4 April 2019, Berita Harian
Nor Raudhah Hj Siren \& Mohamad Zaidi Abdul Rahman (2006), Strategi Mengurus Masjid, Kuala Lumpur: Universiti Malaya Zulkiple Abd Ghani (2003), Islam, Komunikasi, Teknologi Maklumat, Kuala Lumpur: Utusan Publication and Distributor

Temubual bersama penulis teks khutbah Jumaat Negeri Johor Ustaz Mohd Hafiz bin Abdul Rahman Ketua Penolong Pengarah Pengurusan Masjid Jabatan Agama Islam Negeri Johor pada 18 Februari 2020 